\title{
Caminhos interdisciplinares da teoria crítica em um programa CTS: contradições e potencialidades
}

\author{
Gilson Leandro Queluz \\ Universidade Tecnológica Federal do Paraná
}

\section{Resumo}

Neste artigo pretendemos discutir potencialidades e contradições presentes no desenvolvimento de um programa de estudos em ciência e tecnologia e sociedade (CTS), o Programa de Pós-Graduação em Tecnologia da Universidade Tecnológica Federal do Paraná (PPGTE), criado em 1995, a partir de uma orientação inicial derivada da teoria crítica, especialmente em sua vertente habermasiana. Neste sentido, analisaremos algumas teses específicas de Jürgen Habermas, como interpretadas por João Augusto Bastos, criador deste programa, em seu esforço de superação das bases instrumentais de compreensão da tecnologia, tendo em vista a exaltação de seu potencial emancipatório, como fundamento essencial de uma abordagem situada de estudos em ciência, tecnologia e sociedade (CTS). Ressaltaremos, o caráter não linear deste processo e a importância da teoria crítica ampliada e estrita, para a elaboração de uma práxis baseada em um materialismo interdisciplinar no campo CTS.

Palavras-chave: Teoria crítica. Ciência. Tecnologia e sociedade (CTS). Interdisciplinaridade 


\section{Interdisciplinary pathways of critical theory in a CTS program: contradictions and potentials}

In this article, we intend to discuss the potentials and contradictions in the development of a program of studies in science, technology and society (STS), the Graduate Program in Technology of the Federal Technological University of Paraná (PPGTE), created in 1995, based on an initial orientation derived from critical theory, especially in its Habermasian trend. Thus, we analyze some specific thesis of Jürgen Habermas, as interpreted by Bastos, creator of this graduate program, in his effort to overcome the instrumental bases of understanding of technology, in order to exalt its emancipatory character as the essential foundation for a situated approach of studies in Science, Technology and Society (STS). We emphasize the nonlinear character of this process and the importance of strict and expanded critical theory for developing a praxis based on an interdisciplinary materialism in the field of CTS.

Keywords: Critical Theory. Science, Technology and Society (STS). Interdisciplinary.

\section{Formas Interdisciplinarias de la teoría crítica en un programa CTS: contradicciones y potencialidades}

En este artículo nos proponemos analizar las potencialidades y contradicciones en el desarrollo de un programa de estudios de la ciencia, tecnología y sociedad ( CTS ), el Programa de Posgrado en Tecnología de la Universidad Tecnológica Federal de Paraná ( PPGTE ), creado en 1995, desde una orientación inicial derivada de la teoría crítica, especialmente en su tendencia habermasiana. En este sentido, se analizan algunas tesis especificas de Jürgen Habermas, según la interpretación de João Augusto Bastos, creador de este programa, en su esfuerzo por superar las bases instrumentales de la comprensión de la tecnología con el fin de elevar su potencial emancipador como fundamento esencial de un enfoque situado para los estudios en Ciencia, Tecnología y Sociedad (CTS ). Hacemos hincapié en el carácter no lineal de este proceso y la importancia de la teoría crítica estricta y ampliada, para el desarrollo de una praxis basada en un materialismo interdisciplinario en el campo CTS.

Palabras-clave: Teoría Crítica. Ciencia. Tecnologíay Sociedad(CTS). Interdisciplinaridad. 


\section{Introdução}

Os caminhos para a constituição de um processo educacional que enfatize as relações entre ciência, tecnologia e sociedade são múltiplos, pois estão sempre em diálogo com contextos sócio-históricos distintos. Neste artigo pretendemos discutir potencialidades e contradições presentes no desenvolvimento de um programa de estudos em ciência e tecnologia e sociedade, o Programa de Pós-Graduação em Tecnologia da Universidade Tecnológica Federal do Paraná (PPGTE) ${ }^{1}$, criado em 1995, a partir de uma orientação inicial derivada da teoria crítica² $^{2}$ especialmente a de caráter habermasiano. Verificaremos em escritos do idealizador do programa supracitado, João Augusto Bastos, a sua vinculação à teoria crítica como método de compreensão das relações entre tecnologia e sociedade. Este diálogo com a teoria crítica apresenta variação no tempo, indo da proximidade com a teoria crítica em sentido amplo ${ }^{3}$, com a reflexão sobre politecnia, até a adesão a um dos modelos de teoria crítica no sentido restrito ${ }^{4}$. Neste sentido, analisaremos as teses específicas de Jürgen Habermas, como interpretadas por Bastos, em seu esforço de superação das bases instrumentais de compreensão da tecnologia, tendo em vista a exaltação de seu caráter emancipatório, como fundamentos originários de uma abordagem situada de estudos em ciência, tecnologia e sociedade (CTS). Temos consciência que, ao enfatizarmos as bases teóricas do PPGTE, momentaneamente ocultamos os processos concretos que envolvem a institucionalização educacional em sua materialidade, em seus labirintos administrativos e racionalidades burocráticas, no esforço coletivo de trabalhadores docentes e técnicos, nos sonhos e aspirações que movem os discentes, nos complexos fios que nos unem aos movimentos

1. No início de 2014, o PPGTE, aprovou em seu colegiado a mudança de nome do programa, para Programa de Pós-Graduação em Tecnologia e Sociedade.

2. 0 termo refere-se ao conceito primeiramente proposto por Max Horkheimer (1895-1973) no estudo "Teoria Tradicional e Teoria Crítica", de 1937 (Horkheimer, 2003), e desenvolvido por diversos autores ligados à denominada "Escola de Frankfurt", como Adorno, Benjamin e Marcuse. Dentre as principais obras destes autores, destacamos: Dialética do Esclarecimento de Adorno e Horkheimer(1985), Passagens de Benjamin(2006) e A Ideologia da Sociedade Industrial de Marcuse(1978). Na contemporaneidade destacamos como continuadores desta tradição, especialmente nos seus aportes para a discussão das relações entre ciência, tecnologia e sociedade, Jürgen Habermas e Andrew Feenberg (2002). Para uma coletânea dos escritos dos principais autores da teoria crítica, ver: Benjamin; Horkheimer; Adorno; Habermas(1975). Para estudos introdutórios da Teoria Crítica, ver: Nobre (2004), Mattos (2006), Velasco(2003). Para um estudo aprofundado, ver Wiggershaus (2002).

3. Segundo Marcos Nobre, a teoria crítica em sentido amplo designa um campo que já existia previamente à sua conceituação pelo próprio Horkheimer, isto é, o campo do marxismo. Ver: Nobre. (2004, p. 22)

4. A conceituação de teoria crítica a partir da interpretação do pensamento de Marx por Horkheimer pode ser compreendida por teoria crítica no sentido restrito. A teoria crítica produziu vários modelos, dentre eles o habermasiano. Ver: Nobre. (2004, pp. 22-24) 
sociais e aos contextos regionais e nacionais. Ou seja, fragmentamos uma totalidade, em sua fértil e contraditória ebulição. Porém, consideramos que as ideias aqui apresentadas foram e são elementos constitutivos da realidade e que, na sua dialética processual, percorrem os caminhos entre base e superestrutura, borrando fronteiras, materializando novas realidades e desmaterializando velhas tendências, constituindo-se, portanto, em realidade material enunciativa constante. Deste modo, percebemos que a reflexão fundante, proporcionada pela teoria crítica, permitiu uma pluralidade na compreensão dos fenômenos CTS, abrindo a possibilidade de pesquisas interdisciplinares originais.

Gostaríamos, também, de esclarecer que não pretendemos realizar uma análise crítica das ideias de Habermas, as quais em sua maioria, inclusive, não são professadas pelo autor ${ }^{5}$, porém, demonstrar as peculiaridades interpretativas desenvolvidas pelo prof. João Augusto Bastos, que abriram caminhos na constituição gradual de um programa CTS, com temas centrais como tecnologia e trabalho e tecnologia e cultura.

\section{Uma interpretação peculiar: da politecnia à teoria crítica habermasiana}

O Programa de Pós-Graduação em Tecnologia (PPGTE) foi criado em 1995, tendo como seu principal artífice e coordenador, nos seus primeiros anos, o prof. João Augusto Bastos ${ }^{6}$. A criação do programa deu-se em um quadro complexo que interseccionou políticas institucionais de apoio ao ensino superior e afirmação da pós-graduação e políticas públicas pontuais de apoio à implementação de mestrados em tecnologia nos principais centros federais de educação tecnológica (CEFETs) do País, ou seja, Minas Gerais, Rio de Janeiro e Paraná, visando ao desenvolvimento de centros de pesquisas sobre tecnologia e educação tecnológica nestas instituições.

A constituição do programa também foi marcada pela presença da teoria crítica no pensamento de Bastos, seja em um sentido amplo, como na sua reflexão sobre politecnia, seja em um sentido restrito, com sua posterior adesão à teoria crítica de Jürgen Habermas.

5. Para uma visão crítica sobre a obra de Habermas, ver: Thomassen (2008) e Sitton (2003), especialmente o capítulo 6.

6. O prof. João Augusto Bastos é licenciado em filosofia com doutorado no Institut Catholique de Paris (PUC), França. No momento de criação do PPGTE era analista em ciência \& tecnologia, do Conselho Nacional de Desenvolvimento Científico e Tecnológico, cedido ao então CEFET-PR, hoje Universidade Tecnológica Federal do Paraná. 
A reflexão de Bastos sobre as relações entre tecnologia e sociedade procede de uma visão militante sobre a educação tecnológica ${ }^{7}$, que o levaria inicialmente a adotar o conceito de politecnia em textos produzidos ao longo dos anos 80 .

As considerações desenvolvidas até aqui tentaram analisar sumariamente o quadro amplo e complexo da educação técnica e profissional, inserindo-a num contexto avançado das técnicas e da sociedade moderna assumindo porém um princípio educativo novo e criativo, a formação politécnica. (Bastos, 1991, pp. 62-63)

Para ele, o ensino politécnico poderia conduzir o cidadão a compreender os processos de produção "na sua totalidade e nos seus envolvimentos tecnológicos", possibilitando a apreensão pelo trabalhador da "substância da atividade laboriosa", ou seja, a compreensão do trabalho como ação transformadora da natureza e princípio educativo fundamental. (Bastos, 1991, p. 54)

Os princípios politécnicos também permitiriam a visualização de um materialismo interdisciplinar, característico da teoria crítica, no processo educacional de transmissão das técnicas que se desenvolveria "através da visão histórica e globalizante dos processos tecnológicos e não mediante comunicação parcelada de conhecimentos" (Bastos,1991, p. 55). Bastos argumentava que, para o desenvolvimento desta visão interdisciplinar, seria importante o resgate da história das técnicas, vista como um traço vivo e "dinâmico entre as bases científicas e a transição para as novas técnicas”. (Bastos,1991, p. 61)

Dentro da tradição marxista, uma das bases do posteriormente denominado materialismo interdisciplinar está na análise de Lukács, empreendida em História e Consciência de Classe, sobre o estatuto do conhecimento na sociedade capitalista ${ }^{8}$. Estas concepções foram retomadas e revistas por Horkheimer, que, ao longo da década de 30, por exemplo, nos artigos “Teoria Tradicional e Teoria crítica" (Horkheimer, 2003) e "A Presente Situação da Filosofia Social e as Tarefas do Instituto Social de Frankfurt" (Horkheimer, 1993), proporia um programa de pesquisa interdisciplinar, a ser realizado pelo Instituto Social de Frankfurt, que fosse capaz de elaborar um diagnóstico do capitalismo tardio e de criar novas relações entre teoria e prática que possibilitassem a superação dos processos de reificação social. Este processo reificador estaria presente nos próprios 'processos de demasiada especialização científica que conduziam

\footnotetext{
7. Lembremos com Michael Löwy do papel central desenvolvido pelos intelectuais como produtores diretos da esfera ideológica, criadores em alto grau de produtos ideológicos-culturais, ver; Löwy. (1979, p. 1)

8. Sobre o materialismo interdisciplinar em Lukács, ver: Nobre (1996).
} 
a uma compreensão fragmentada da realidade". 9 Neste sentido, Horkheimer contrapunha uma abordagem que reunisse as ciências sociais, a filosofia social, a psicologia social, a economia política e uma teoria da cultura, em um esforço interdisciplinar crítico de compreensão das contradições da sociedade capitalista, calcado no materialismo dialético. ${ }^{10}$ Esta abordagem permitiria, também, uma superação das concepções mecanicistas da relação entre base e superestrutura, presentes no marxismo ortodoxo. Ao longo da década de 40, após a transferência do instituto para os Estados Unidos, Adorno e Horkheimer indicaram os limites do seu materialismo interdisciplinar, ao constatar que

se se tratasse apenas dos obstáculos resultantes da instrumentação desmemoriada da ciência, o pensamento sobre a questões sociais poderia, pelo menos, tomar como ponto de partida as tendências opostas à ciência oficial. Mas também estas são presas do processo global de produção. Elas não se modificaram menos do que a ideologia à qual se referiam. (Adorno; Horkheimer, 1985, p. 12)

Consideramos que o diálogo com a tradição marxista, realizada por Bastos em sua reflexão sobre politecnia, deixou permanências em seu pensamento, como: a negação de uma visão instrumental de tecnologia; a importância da categoria "trabalho" para a compreensão da tecnologia e do processo educativo; a ênfase no materialismo interdisciplinar, com a compreensão plural e plena das relações entre teoria e prática como base da produção dos conhecimentos técnicos e científicos. Estas permanências estão expressas em escritos posteriores, quando já se aproximara da teoria crítica na vertente habermasiana,

O entendimento da educação tecnológica provém de uma concepção ampla de educação, que preencha os estágios construídos nos processos básicos da formação humana, privilegiando as vertentes do trabalho, do conhecimento universalizado e da inovação tecnológica.

Trata-se de uma concepção básica que não admite aceitar a técnica (de trabalho ou de produção) como autônoma por si só e, consequentemente, não determinante de resultados econômicos e sociais. Ela resulta do enlace historicamente engendrado nas relações sociais de conduzir o processo de produção da sociedade de acordo com a forma e o rumo do desenvolvimento então estabelecido. Desta forma, a técnica de produção e de trabalho tem a ver com as desigualdades entre indivíduo, classes, setores e regiões. (Bastos, 2000b, p. 35)

9. Sobre a questão do materialismo interdisciplinar como uma das bases da Teoria Crítica, como proposta por Horkheimer, ver: Bonß(1993), Gomes(2010) e Honeth (1996).

10. Um exemplo de pesquisa interdisciplinar empreendida pelo Instituto Social de Frankfurt são os Estudos sobre Autoridade e Família, ver Horhheimer. (2003, pp. 76-150) 
Bastos considera que a educação tecnológica, dominada pela racionalidade técnica e pela ação instrumental, acaba por ser uma reprodutora de tais desigualdades, constituindo-se em instrumento de reificação social, que sufoca seu potencial emancipatório.

É nesta perspectiva que o pensamento habermasiano será central para Bastos, principalmente no seu esforço de resgatar o caráter emancipatório da modernidade. Como aponta William Outhwaite, a “Modernidade (...) vista como oferecendo uma promessa altamente condicional de autonomia, justiça, democracia e solidariedade, agora parece ser a categoria organizadora, através da qual pode se entender o pensamento de Habermas" (2000, p. 3) ${ }^{11}$. Velasco, por sua vez, destaca a intencionalidade de Habermas em "guiar com uma finalidade emancipatória o caminho da práxis (Velasco, 2003, p. 12). Bastos afirmava que, em Habermas, "A humanidade é convidada a reconstruir o projeto de modernidade tentando restabelecer o caráter emancipador da razão”. (Bastos, 2000b, p. 32)

Habermas, como partícipe da teoria crítica, inicialmente aproximou-se de um marxismo ortodoxo, gradualmente abandonado em prol de um marxismo revisionista. Ao realizar, por exemplo, em Técnica e Ciência como ldeologia uma crítica à tecnocracia, Habermas propõe uma distinção entre os conceitos de trabalho e interação. Trabalho compreendido como "agir racional-com-respeito-a-fins, seja o agir instrumental, seja a escolha racional, seja a combinação dos dois" (Habermas, 1975, p. 310), interação compreendida como um agir comunicativo mediatizado simbolicamente (Habermas, 1975, p. 311). A partir destas premissas, Habermas propôs em seu livro Para uma Reconstrução do Materialismo Histórico(1983) uma releitura do materialismo histórico, no qual destaca-se uma "teoria da evolução social, tendo como princípio motor o aprendizado" (Dupeiryx, 2012, p. 81). Para ele, na elaboração dos novos modos de produção, as "estruturas normativas e as performances sociocognitivas" desempenhariam um "papel tão importante quanto as forças produtivas" (Dupeiryx 2012, p. 82). ${ }^{12}$ Para Bastos, a centralidade dada aos tipos de aprendizado sociocognitivos - os de ordem instrumental, técnica, científica -, presentes na transformação das forças produtivas, e aos de tipo comunicativo abriria férteis possibilidades de reflexão sobre a educação tecnológica. Para ele, a gênese da tecnologia e seu desenvolvimento é um processo de aprendizagem, não por seu uso externo ou manipulativo, mas "pelo poder criativo e emancipatório". Portanto, a aprendizagem tecnológica estaria "estruturada na racionalidade que ultrapassou os limites das aplicações técnicas, que busca o âmago da linguagem

11. Para uma análise do discurso da modernidade ver: Habermas (2002).

12. Observe-se que esta interpretação do materialismo histórico, segundo Velasco (2003, p. 22), seria criticada por autores como Muguerza. 
comunicativa, inserida na história das ciências e das técnicas" (Bastos et ali, 2000a). Bastos, ao longo dos anos 90, adotou os princípios da ação comunicativa elaborados por Habermas, como forma de “liberação da razão moderna de suas premissas exclusivamente subjetivas e individualistas, buscando a superação na conciliação das perspectivas do mundo da vida" (Bastos, 2000b, p. 33). A ação comunicativa possibilitaria a produção de "consensos emancipatórios coletivos" (Bastos, 2000b, p. 33), rompendo com a dissociação entre o mundo da vida e o sistema causador das patologias do mundo moderno. ${ }^{13}$ Debora Cook (2004) sintetiza um conjunto de críticas à divisão entre mundo da vida e sistema, proposta por Habermas, por exemplo, já que o sistema político e econômico nunca é meramente instrumental, mas está profundamente marcado pelas estruturas da cultura. A ação comunicativa seria o "élan constitutivo da realidade social e do próprio saber", tendo o conhecimento, portanto, um caráter "dialógico, intersubjetivo, que cria espaço para o diverso e não para o idêntico" (Bastos, 2000b, p. 33). Para combater a coerção do sistema na tecnologia e na educação tecnológica seria fundamental a compreensão habermasiana do conhecimento como resultado "da ação do sujeito em suas preocupações cotidianas e interesses humanos enraizados em condições históricas e sociais" (Bastos, 2000b, p. 32). Bastos, sintetizando a discussão encontrada na obra de Habermas, Conhecimento e Interesse, escreveu: 0 interesse técnico "significa o controle técnico sobre os objetos naturais, o que constitui o saber instrumental, as explicações científicas e os procedimentos técnicos". 0 interesse prático "traz o significado das dimensões sociais e da cotidianidade dos homens". O interesse emancipatório "torna possível a ação comunicativa, a interação social e a ciência social crítica (Bastos, 2000b, p. 32). ${ }^{14}$ A presença dos interesses técnicos, práticos e emancipatórios no próprio âmago da ciência e da tecnologia seriam centrais na argumentação de Bastos contra a visão hegemônica da neutralidade dos conhecimentos científicos e tecnológicos em uma instituição tecnológica. Desta forma, para ele, “a recuperação da escola e da educação tecnológica passaria pela racionalidade comunicativa, pela ação comunicativa que tornaria a educação parceira da tecnologia, objetivando a construção do laboratório do conhecimento". (Bastos, 2000b, p. 40)15

13. Sobre as relações entre mundo da vida e sistema, ver Habermas (2012) especialmente o capítulo VI, pp. 205355. Ver: Cooke. (2004, pp. 35-37)

14. Ver Habermas(1982). Velasco comenta que esta concepção, apesar de logo abandonada por Habermas, teria uma ampla recepção na filosofia da educação. (Velasco, p.31)

15. Kominek (2000, p. 55) afirmaria, no mesmo sentido, "a fecundidade que a proposta habermasiana de resgate do potencial comunicativo da razão pode representar para a reflexão sobre a educação tecnológica, uma vez que põe em foco as interações sociais entre os sujeitos comunicativamente competentes que, através da linguagem, entendem-se entre si, tendo como pano de fundo o seu mundo da vida". 
Esta proposta da educação tecnológica como laboratório do conhecimento não é propriamente nova; sendo, inclusive, em outros contextos, usada como instrumento de controle social e racionalização. Porém, em Bastos, assumiria um papel de democratização radical do conhecimento, permitindo a erosão das hierarquias acadêmicas, constituindo-se em elemento de persuasão para a importância da construção coletiva dos saberes, redobrando a atenção para os caminhos dialógicos entre teoria e prática e os cuidados para as relações entre saber e poder. Para ele, a pesquisa pode transformar-se "numa atitude cotidiana, não reservada exclusivamente ao especialista, mas ao cidadão, que é convocado a construir o conhecimento a partir do cotidiano" (Bastos, 1998, p. 60). Neste processo, as características teóricas e práticas da pesquisa associam-se, possibilitando um “questionamento sistemático, crítico e criativo, provocando intervenções inovadoras no processo de construção de caminhos científicos para melhor intervir na realidade" (Bastos,1998, p. 60). Estas pesquisas tenderiam a assumir um aspecto interdisciplinar cooperativo por serem fruto de atividades comunicativas que provocam a "mediação entre a filosofia e as ciências, a ciência e a tecnologia no mundo vivido" (Bastos,1998, p. 61). Ao recolher os diversos fragmentos até então "isolados no mundo objetivo e social", coloca-se a possibilidade de que no "mundo das ciências não haverá mais hierarquias e nenhuma delas ditará sozinha a verdade absoluta" (Bastos, 1998, p. 61). ${ }^{16}$ Bastos, neste sentido, segue os passos de Habermas (1992, pp. 527-572), que na sua obra, Teoria da Ação Comunicativa, retomou as principais temáticas referentes à teoria crítica, inclusive, o materialismo interdisciplinar, visto agora como projeto de estudos interdisciplinares, procurando destacar a possibilidade de sua retomada em um contexto de rompimento com a filosofia da história a ele subjacente, e de adoção dos pressupostos da teoria da ação comunicativa. Para Bastos, estes princípios seriam a base para o futuro desafio de elaboração de uma "pedagogia da técnica", que se caracterizaria "pelo deslocamento do centro de gravidade dos atos específicos de trabalho para o entendimento mais global das atividades", a partir da razão comunicativa. Estes princípios foram experimentados em projetos coletivos como o "Produção e Apropriação do Conhecimento Tecnológico" (Bastos et. al., 2000a), baseado no diálogo democrático entre docentes, discentes e trabalhadores de diversos setores produtivos.

16. larozinski (2000, p. 83) na sua dissertação de mestrado, orientada por Bastos, afirmaria sobre o papel da interdisciplinaridade na educação tecnológica: “a interdisciplinaridade apoiada na Teoria da Ação Comunicativa visa à superação do trabalho isolado, do fracionamento do saber e da racionalidade técnica e instrumental, tão fortemente atrelada aos aspectos cognitivos-instrumentais. Baseia-se num conceito amplo de razão, em que os sujeitos das mais diferentes áreas formam parcerias, numa atitude de reciprocidade, de respeito e aceitação das individualidades, utilizando-se do processo dialógico para a construção do conhecimento coletivo". 
Esta relação entre conhecimento e interesse, somada ao deslocamento provocado pelas premissas críticas de Habermas diante do materialismo dialético, possibilitou a Bastos assumir como centrais para as pesquisas sobre tecnologia e sociedade as relações entre trabalho e interação, nos seguintes termos:

pela ação comunicativa, mediada pela linguagem do trabalho como interação e não como ação puramente instrumental, no âmbito da racionalidade aqui exposta, as relações com a ciência e a tecnologia se reconstituem, explorando os espaços de comunicação no interior dos grupos e das tecnologias para reencontrar novas formas de linguagem no contexto da sociedade produtiva. (Bastos, 1998,p. 64)

Habermas desenvolve esta temática em diversos momentos de sua trajetória, por exemplo, no artigo Trabalho e Interação, de 1965 (Habermas,1997), e na obra Conhecimento e Interesse (Habermas, 1982, pp. 217-218). A ênfase na comunicação interativa levaria a uma crítica por Habermas do conceito de reificação na tradição marxista e de seu foco no conceito de trabalho social como o real sustentáculo da evolução histórica, segundo Pauline Johnson, deslocando-o para uma concepção em que a "reificação ocorre quando uma razão instrumental expandida procura colonizar a racionalidade específica de acordos alcançados comunicativamente". ${ }^{17}$

Nos próximos tópicos, analisaremos dois campos de pesquisa desenvolvidos no PPGTE a partir destas premissas e posteriormente modificados por outras hibridações teóricas: tecnologia e trabalho, e tecnologia e interação.

\section{Tecnologia e interação}

O deslocamento da filosofia da consciência e do sujeito para a filosofia da linguagem, implícita no agir comunicativo de Habermas, defendida por Bastos, conduziu à constituição de uma linha de pesquisa ${ }^{18}$, na qual os processos de interação social, constituintes e constituídos na tecnologia e no trabalho, são a preocupação preponderante. Podemos constatar na concretude do processo de produção do conhecimento pelos pesquisadores desta linha que, contraditoriamente, não houve uma adesão restrita às premissas habermasianas, mas estas operaram como uma ponte para o diálogo com outras concepções teóricas que valoram a linguagem em suas imbricações com a cultura material.

17. Ver, Johnson. (2004, p. 111)

18. As linhas de pesquisa Tecnologia e Interação e Tecnologia e Trabalho foram organizadas em 1999. No mesmo período foi criada a linha de pesquisa Tecnologia e Desenvolvimento, que não será analisada neste artigo. 
As próprias reflexões habermasianas sobre as concepções de conhecimento e linguagem presentes no pragmatismo levaram a uma retomada, por alguns pesquisadores, da semiótica, especialmente, mas não exclusivamente, em sua tendência peirceana. ${ }^{19}$ A semiótica auxiliou os debates sobre a decodificação dos processos de construção de significados inscritos na materialidade da $\operatorname{arte}^{20}$, do design $^{21}$, da fotografia ${ }^{22}$, do cinema ${ }^{23}$, da publicidade ${ }^{24}$, entre outros.

A ênfase de Habermas na emancipação possível, mediante a ação comunicativa, por sua vez, trouxe a abertura para a recepção das teorias bakhtinianas do discurso e sua perspectiva utópica da polifonia. ${ }^{25}$ Para Bakhtin, deve-se ter claro a vinculação entre linguagem e atividades humanas. Os enunciados são produzidos no próprio processo de interação e em condições sociais e objetivas específicas. E os gêneros discursivos, nos quais os gêneros literários estariam incluídos, são conjuntos relativamente estáveis de enunciados produzidos em determinada esfera da atividade humana (Bakhtin, 2003, p. 266). Neste sentido, a tecnologia, em seu nascedouro das relações sociais de produção, é permeada e permeia a linguagem e a cultura.

Os vínculos com a teoria crítica e a releitura do materialismo dialético empreendidos por Habermas conduziram a busca de referenciais mais concretos para problematizar as relações entre cultura e vida material, cultura e tecnologia. Esta é a visão básica que norteia a concepção de Raymond Williams da necessidade de um materialismo cultural, uma teoria "das especificidades da produção material da cultura e da literatura no interior do materialismo histórico" (Williams, 2009, p. 15). A linguagem é um tipo especial de prática material, uma prática da sociabilidade humana (Williams, 2009, p. 220), uma atividade "social reciprocamente compartilhada que se acha encravada em relações ativas dentro

19. Habermas(1987) refletiria sobre a importância do pensamento peirceano, no capítulo 5 , A Lógica da pesquisa em Ch. S. Peirce, da obra Conhecimento e Interesse. Nele, Habermas enfatiza a importância de Peirce da passagem de uma filosofia da consciência para uma filosofia baseada nas relações comunicativas, porém criticaria os limites de sua percepção da importância da intersubjetividade no processo comunicativo. Sobre a relação Habermas e Peirce ver: Silveira (2013).

20. Ver: Costa (2009).

21. Ver: Cresto (2009).

22. Ver: Villar (2008).

23. Ver: Mikosz (2003).

24. Ver Kaminski (2003).

25. Ressalte-se a importância das concepções bakhtinianas de Carlos Alberto Faraco - então professor visitante no programa -, expressas exemplarmente no seu livro Linguagem e Diálogo (2003), para a constituição da linha de pesquisa Tecnologia e Interação. Para uma aproximação do pensamento de Habermas e Bakhtin, ver: Fontes (2002). Para um exemplo de dissertação que utiliza argumentos bakhtianos para a compreensão das interações entre tecnologia e cultura popular, ver: Sugayama (2012). 
das quais cada movimento constitui uma ativação do que já está compartilhado ou recíproco e pode converter-se em tal" (Williams, 2009, p. 222). Portanto, podemos perceber tanto a produção material da ordem cultural, quanto perceber a cultura como força produtiva, como um dos "meios de produção e reprodução da vida real". (Williams, 2009, p. 126)

As concepções de Williams auxiliaram o desenvolvimento do campo de estudos denominado Estudos Culturais, que teve como um dos principais articuladores Stuart Hall. A recepção dos Estudos Culturais na América Latina foi empreendida por autores como Martin Barbero, Nestor Garcia Canclini e Beatriz Sarlo. Estes autores promoveram hibridizações teóricas no forte esforço de problematizar as relações entre materialidade e cultura no contexto latino-americano, possibilitando uma nova compreensão da comunicação, da tecnologia e do trabalho. Hibridizações que, em diversos níveis, foram incorporadas e transformadas por pesquisadores do PPGTE. ${ }^{26}$

As pesquisas desenvolvidas a partir destes novos aportes teóricos, possibilitados por um diálogo inicial com a teoria crítica no modelo habermasiano, conduziram dialeticamente a uma nova síntese, expressa no nome assumido pela linha em 2011, Mediações e Culturas:

A escolha por Mediações também tem por objetivo realçar as abordagens plurais fomentadas na linha e no programa. Tecnologias, nesta acepção, não se restringem aos artefatos e instrumentos, embora estes as permeiem. Assume-se que o ser humano se faz coletivamente pelas relações sociais, nas mediações (materiais ou simbólicas). Nesta perspectiva, tecnologias são sempre mediações sociais (materiais ou simbólicas), situadas e circunstanciadas axiológica, cultural e historicamente. Por culturas compreendem-se os conjuntos articulados de ações e restrições, interações e influências, relações e técnicas, tendências e desvios, motivações e direcionamentos, recursos e possibilidades presentes em uma sociedade em determinado momento e espaço. Neste sentido, culturas incluem tecnologias, condicionando e transformando-as dialética e dialogicamente. (PPGTE, 2014)

Como podemos perceber, esta definição, apesar de distanciar-se da teoria crítica de cunho habermasiano, pela sua ênfase na produção coletiva do ser humano nas relações sociais de produção constituídas historicamente e nas tecnologias como mediações sociais, permanece no âmbito da tradição da teoria crítica em sentido amplo. 


\section{Tecnologia e trabalho}

Como vimos, a militância intelectual de Bastos, pelo desenvolvimento de uma pedagogia da técnica, o conduziu, primeiramente, a uma aproximação com a teoria crítica, na qual destacou-se o diálogo com o conceito de politecnia e com a questão da centralidade do trabalho na dimensão ontológica e histórica. Neste processo de compreensão do materialismo histórico como tendo um caráter interdisciplinar, Bastos indicou a importância da história das técnicas. Mediante a contextualização histórica, seria possível perceber as interações entre tecnologia, trabalho e educação em toda sua complexidade. Bastos retoma a proposição marxista de uma história crítica da tecnologia, por meio da qual seria possível "revelar o modo de proceder do homem para com a natureza, o processo imediato de produção de sua vida e assim elucidar as condições de sua vida social e as concepções mentais que delas decorrem". (Marx, 1978, p. 425)

É nesta perspectiva que Bastos volta-se para a obra do arquiteto e historiador da técnica e da tecnologia, Ruy Gama, que, baseado em uma concepção fortemente marxista, desenvolveu em sua obra Tecnologia e Trabalho na História uma extensa discussão sobre o conceito de tecnologia em sua historicidade, propondo o conceito da tecnologia moderna como "ciência do trabalho produtivo" (Gama, 1986, p. 185). Nesta aproximação de Bastos com Gama, opera-se uma contradição fundamental com a visão habermasiana, pois o trabalho volta a ter a centralidade. Porém, o que parece ter fascinado Bastos e que apresenta uma coerência marcante com a teoria crítica de modo geral, sendo decisivo para a constituição da linha de pesquisa, foi o potencial interdisciplinar do conceito de Gama. Não pretendo desenvolver aqui uma análise detida deste conceito, já desenvolvida em Leite e Queluz (2005), mas é importante ressaltar que, para Gama, a tecnologia poderia ser expressa em uma figura geométrica, o tetraedro, com o objetivo de demonstrar sua dinâmica. As quatro faces ou dimensões da tecnologia seriam, “I - A Tecnologia do trabalho, II - A Tecnologia dos Materiais, III - A Tecnologia dos Meios de Trabalho, IV - A Tecnologia Básica ou Praxiologia (Gama,1986, p. 186). Desta forma, Gama, ao explicitar o caráter plural das relações entre tecnologia e trabalho, além de combater os discursos deterministas tecnológicos - combate constituinte da própria área CTS -, abre possibilidades de pesquisas interdisciplinares na área tecnologia e sociedade. Por exemplo, na dimensão da tecnologia do trabalho seria possível pesquisar

questões relativas aos movimentos, gestos e atitudes no trabalho, intimamente ligadas à questão dos tempos de trabalho. A divisão do trabalho em seus diversos níveis (social, profissional ou as formas mais antigas de divisão por sexo ou idade), e as relações entre 
os trabalhadores no processo de trabalho (...) assim como o que se refere às formas de transmissão do conhecimento e das habilidades no sistema de aprendizagem ou no sistema escolarizado". (Gama,1986, p. 188)

Ou seja, apenas nesta dimensão, percebe-se um programa amplo de pesquisa em tecnologia e sociedade, que inclui a análise das formas de organização e racionalização das relações sociais de produção, reflexões sobre gênero e sobre a educação profissional-tecnológica, em sua historicidade específica. ${ }^{27}$ Temáticas que, ao longo dos anos, tornaram-se centrais nos estudos desenvolvidos na linha de pesquisa, potencializados na interface com outras dimensões materiais e imateriais. Dentro desta perspectiva, a consolidação do campo da história da tecnologia no PPGTE foi uma das instâncias de contato com o campo CTS, por intermédio das obras de autores como David Noble, Thomas Hughes e David Nye.

Se a visão de Gama, dentro do âmbito da teoria crítica, por um lado, permitiu este olhar plural sobre as relações entre tecnologia e trabalho; por outro, apresentou uma clara insuficiência na problematização das relações entre tecnologia e cultura, ao limitar-se a uma ortodoxa compreensão das relações entre base e superestrutura. A reflexão e a crítica destas relações, fundamentais para a compreensão de qualquer formação social e, especialmente, para a sociedade contemporânea, ocuparam um papel central na teoria crítica, em obras de pensadores como Walter Benjamin, Theodor Adorno, Horkheimer, Herbert Marcuse e Habermas ${ }^{28}$. Os aportes destes autores à problemática, conjugados à tradição da antropologia cultural, também representada no corpo docente do PPGTE ${ }^{29}$, permitiram o desenvolvimento de pesquisas que procuraram compreender a tecnologia como fenômeno que demonstra o esmaecimento das fronteiras entre base e superestrutura. Assim, podemos perceber tanto a produção material da ordem cultural, quanto perceber a cultura como força produtiva, "práticas reais, elementos de um processo material total" (Williams, 2009 , p. 130). Esta visão possibilitou o desenvolvimento de estudos que abarcaram desde a cultura organizacional de empresas, cooperativas, sindicatos, até o processo de resistência política e cultural de trabalhadores agrícolas, industriais e artesanais aos processos de desenraizamento e expropriação de seus modos

27. Para exemplo de pesquisas sobre gênero e tecnologia, ver a coletânea: Da Luz; Carvalho; Casagrandelorgs), (2009). Sobre a educação profissional, ver: Garcia; Lima Filho (orgs.) (2010).

28. Para uma crítica à concepção marxista ortodoxa da relação entre base e superestrutura, ver: Habermas (1983), especialmente a terceira parte, Evolução, pp.111-218.

29. Para uma discussão sobre a importância da discussão conceitual sobre cultura, para a compreensão da tecnologia e da cultura organizacional das empresas, ver: Carvalho (1997). 
de vida e produção. ${ }^{30}$ Instigou, também, a reflexão sobre as representações de ciência e tecnologia em manifestações culturais como a literatura, a publicidade e a política ${ }^{31}$.

A forte presença da teoria crítica nesta linha de pesquisa, ironicamente não em sua vertente habermasiana, tem passado por plurais atualizações, com a apropriação do pensamento de autores como Herbert Marcuse e Andrew Feenberg. Estas concepções foram hibridizadas por conceitos advindos de autores latino-americanos, como Álvaro Vieira Pinto, Guerreiro Ramos e Enrique Dussel. ${ }^{32}$ Contudo, ressalte-se não há linearidade neste processo, pois, para alguns pesquisadores e discentes, o materialismo interdisciplinar, em sua práxis, pode incorporar outras tendências teóricas - incorporações movidas pela contraditória coerência da mobilização de indivíduos e coletivos em combates acadêmicos e sociais, pela democratização radical da tecnologia como uma das fontes de transformação social.

\section{Considerações Finais}

Este trabalho procurou apresentar uma reflexão sobre a constituição de um programa de pós-graduação na área CTS, a partir de um dialético processo de apropriação e produção da teoria crítica, especialmente da vertente habermasiana, como compreendida pelo seu principal articulador, o professor João Augusto Bastos.

Este processo foi apresentado com uma certa linearidade que ocultou, parcialmente, outras contradições presentes nas experiências vividas dos fazeres acadêmicos em suas intersecções com as tensões econômicas, políticas, sociais e culturais, presentes em uma universidade de cunho tecnológico, em uma cidade de um país latino-americano. Apontamos, nesta conclusão, algumas destas contradições. A teoria crítica e, especialmente, a prática do materialismo interdisciplinar exigem o comprometimento constante com a atualização e potencialização dos ideais emancipatórios, presentes pluralmente na sociedade. Neste sentido, as práticas produtivistas acadêmicas nem sempre têm possibilitado, com a intensidade necessária, uma interação plena com vozes, fazeres e saberes advindos dos atores sociais das classes populares. Outra contradição, inerente às práticas interdisciplinares, de forma geral, é a dialética entre estruturas

30. Ver: Pereira Netto; Da Luz (2012), Pezarico (2007) e Matiello (2011).

31. Ver: Fanini; Santos (2013) e Queluz (2010).

32. Ver: Queluz; Merkle (2012) e Queiroz (2013). 
disciplinares de formação e atuação marcadas por fortes características identitárias, nas quais se movem os docentes e a fluidez de fronteiras e hibridizações que se fazem necessárias para uma construção interdisciplinar de conhecimentos na área CTS. Este processo tem se mostrado como um desafio constante para docentes e discentes. Outra contradição são os persistentes choques entre o esforço de construção de práticas coletivas interdisciplinares, comprometidas com um caráter emancipatório da ciência e da tecnologia, e a presença implícita, na operacionalidade das políticas universitárias, de conceitos reificadores, marcados pela concepção de neutralidade, linearidade e aceitação do status quo hegemônico de ciência e tecnologia. Porém, estas experiências, situadas em suas singularidades e contradições, podem evidenciar a importância das releituras da teoria crítica para práticas interdisciplinares de estudos CTS nos mais diversos níveis de ensino.

\section{Referências}

ADORNO, Theodor; HORKHEIMER, Max. Dialética do esclarecimento. Rio de Janeiro: Zahar, 1985.

BAKHTIN, Mikhail. Estética da criação verbal. São Paulo: Martins Fontes, 2003. BASTOS, João Augusto S. L. A et ali. Desafios da apropriação do conhecimento tecnológico. Curitiba: CEFET-PR, 2000a.

BASTOS, João Augusto S. L. A. A Educação tecnológica na Sociedade do Conhecimento. In: BASTOS, João Augusto S. L. A (org.) Tecnologia e interação. Curitiba: CEFET-PR, 1998, pp. 53-65.

BASTOS, João Augusto S. L. A. Educação técnico-profissional: Fundamentos, Perspectivas e Prospectiva. Brasilia: SENETE, 1991.

BASTOS, João Augusto S. L. A. O Entorno da Modernidade. In: BASTOS, João Augusto S. L. A lorg.). Memória e modernidade. Curitiba: CEFET-PR, 2000b, pp. 21-44.

BENJAMIN, Walter; HORKHEIMER, Max; ADORNO, Theodor; HABERMAS, Jurgen. Textos escolhidos. São Paulo: Abril, 1975.

BENJAMIN, Walter. Passagens. Belo Horizonte: UFMG, 2006.

BONß, Wolfgang. The Program of Interdisciplinary Research and the Begginings of Critical Theory. In: BONß, Wolfgang; Benhabib, Seyla; McCole, John. On Max Horkheimer: New Perspectives. Cambridge (Mass.): MIT, 1993.

CARVALHO, Marília Gomes de. Antropologia e as Culturas Organizacionais. In: Revista Educação e Tecnologia, Curitiba: CEFET-PR, n. 2, 1997, pp. 107-114. COSTA, Claudia Cristina. Corpos híbridos: a construção do corpo humano na 
modernidade a partir da arte e da tecnologia. 2009. Dissertação (Mestrado em Tecnologial - Programa de Pós-Graduação em Tecnologia, Universidade Tecnológica Federal do Paraná.

COOKE, Deborah. Adorno, Habermas and the Search for a Rational Society. London: NewYork: Routeledge, 2004.

CRESTO, Lindsay. A re-significação da relação entre design e tecnologia na obra dos irmãos Campana. 2009. 264f. Dissertação (Mestrado em Tecnologia) - Programa de Pós-Graduação em Tecnologia, Universidade Tecnológica Federal do Paraná. DUPEYREX, Alexandre. Compreender Habermas. São Paulo: Edições Loyola, 2012. FANINI, Angela Maria Rubel; SANTOS, A. C. Trabalho artesanal e trabalho industrial como elementos de sociabilidade, subjetividade e tragédia em A mão esquerda, de Roniwalter Jatobá. Estudos de Literatura Contemporânea, v. 42, pp. 197-208, 2013. FARACO, Carlos Alberto. Linguagem e diálogo: As ideias linguísticas do Círculo de Bakhtin. Curitiba: Criar, 2003.

FEENBERG, Andrew. Transforming technology: a critical theory revisited. New York: Oxford University Press, 2002.

FONTES, Rejane de Souza. A construção do sujeito através da linguagem: um diálogo entre as teorias de Habermas, Bakhtin, Vygotsky e Foucault. Revista de Educação, PUC-Campinas, Campinas, v. 13, pp. 31-49, 2002.

GAMA, Ruy. A Tecnologia e o trabalho na história, São Paulo: Nobel/Edusp, 1986. GARCIA, Nilson Marcos Dias (Org.); LIMA FILHO, Domingos Leite (Org.). Trabalho, educação e tecnologia: alguns de seus enlaces. Curitiba: Editora da UTFPR, 2010. GOMES, Sônia Pereira. A teoria crítica perante o capitalismo tardio. 2010. $113 \mathrm{f}$. Dissertação (Mestrado em Filosofia) - Programa de Pós-Graduação em Filosofia, Universidade São Judas Tadeu.

HABERMAS, Jürgen. Conhecimento e interesse. Rio de Janeiro: Zahar, 1982.

HABERMAS, Jürgen. O discurso filosófico da modernidade. São Paulo: Martins Fontes, 2002.

HABERMAS, Jürgen. Técnica e ciência como ideologia. In: BENJAMIN, Walter; HORKHEIMER, Max; ADORNO, Theodor; HABERMAS, Jurgen. Textos Escolhidos. São Paulo: Abril, 1975, pp. 303-333.

HABERMAS, Jürgen. Técnica e ciência como ideologia. Lisboa: Edições 70, 1997.

HABERMAS, Jürgen. Teoria de la acción comunicativa, II. Madrid: Taurus, 1992.

HABERMAS, Jürgen. Para a reconstrução do materialismo dialético. São Paulo: Brasiliense, 1983.

HONETH, Alex. Teoria Crítica. In: GIDDENS, Anthony \& TURNER, Jonathan. Teoria Social Hoje. São Paulo: UNESP, 1999, pp. 503-552.

HORKHEIMER, Max. Between philosophy and social science. Selected Early Writings, Cambridge (Mass.) MIT Press 1993. 
HORKHEIMER, Max. Teoria crítica. Buenos Aires: Amorrortu, 2003.

IAROZINSKI, Maristela Heidemann. Contribuições da teoria da ação comunicativa de Jürgen Habermas para a educação tecnológica. 2000. 1001 f. Dissertação (Mestrado em Tecnologial - Programa de Pós-Graduação em Tecnologia, Universidade Tecnológica Federal do Paraná.

JOHNSON, Pauline. Irreconciliable differences? Habermas and feminism, In: FREUNDLIEB, Dieter; HUDSON, Wayne; RUNDELL, John (Eds). Critical Theory After Habermas. Leiden: Boston: Brill, 2004.

KAMINSKI, Rosane. Imagens de Revistas Curitibanas: Análise das Contradições na Cultura Publicitária no Contexto dos Anos Setenta. 2003. 300 f. Dissertação (Mestrado em Tecnologial - Programa de Pós-Graduação em Tecnologia, Universidade Tecnológica Federal do Paraná.

KOMINEK, Andréa M. V. Cultura e tecnologia. In: BASTOS, João Augusto L. A. (Org.). Educação tecnológica imaterial e comunicativa. Curitiba: CEFET-PR, 2000, pp. 57-76. LÖWY, Michael. Para uma sociologia dos intelectuais revolucionários. LECH: São Paulo, 1979.

LUZ, Nanci Stancki da; CARVALHO, Marília Gomes de; CASAGRANDE, Lindamir Salete (Orgs.). Construindo a igualdade na diversidade: gênero e sexualidade na escola. Curitiba: UTFPR, 2009.

MARCUSE, Herbert. A Ideologia da sociedade industrial. Rio de Janeiro: Zahar, 1978. MARX, Karl. O Capital, L. 1. v. 1. São Paulo: Difel, 1978.

MATIELLO, Catiane. Narrativas tecnológicas, desenraizamento e cultura da resistência: história oral de vida de famílias desapropriadas pela construção da Usina Hidrelétrica de Itaipu. 2011. 302f. Dissertação (Mestrado em Tecnologia) Programa de Pós-Graduação em Tecnologia, Universidade Tecnológica Federal do Paraná.

MATTOS, Olgária. A escola de Frankfurt. Moderna: São Paulo, 2006.

MIKOSZ. José Eliézer. Inovação tecnológica e desenho Animado. 2003.125 f. Dissertação (Mestrado em Tecnologia) - Programa de Pós-Graduação em Tecnologia, Universidade Tecnológica Federal do Paraná.

NOBRE, Marcos. Teoria crítica. Zahar: Rio de Janeiro, 2004.

NOBRE, Marcos. Lukács e o materialismo interdisciplinar. In: ANTUNES, R. \& RÊGO, W.L. Lukács: um Galileu no século XX. São Paulo: Boitempo, 1996, pp. 74-83. OUTHWAITE, William (Ed). The Habermas reader. Polity Press: Cambridge,UK, 2000.

PEREIRA NETTO, Nilo Silva; DA LUZ, Nanci Stancki . Mundialização do capital e divisão sexual do trabalho: a walmartização das operadoras de checkout. Em Debate (UFSC. Online), v. 1, pp. 194-213, 2012.

PEZARICO, Giovanna. Saberes e Poderes Mediados Pela Tecnologia: Uma Análise 
em Fábricas da Indústria de Linha Branca no Sudoeste do Paraná. 2007. 182 f. Dissertação (Mestrado em Tecnologia) - Programa de Pós-Graduação em Tecnologia, Universidade Tecnológica Federal do Paraná.

PPGTE (Programa de Pós Graduação em Tecnologia). Linha de Pesquisa Mediaçõese Cultura. Disponível em: <http://www.utfpr.edu.br/curitiba/estrutura-universitaria/ diretorias/dirppg/programas/ppgte/areas-pesquisa/tecnologia-e-interacao>. Acesso em: 15 maio 2014.

QUEIROZ, Ivo Pereira de. Fanon, o reconhecimento do negro e o novo humanismo: horizontes descoloniais da tecnologia. 2013. $221 \mathrm{f}$. Tese (Doutorado em Tecnologia) - Programa de Pós-Graduação em Tecnologia, Universidade Tecnológica Federal do Paraná.

QUELUZ, Gilson Leandro; LIMA FILHO, Domingos Leite. A tecnologia e a educação tecnológica: elementos para uma sistematização conceitual. Educação \& Tecnologia, Belo Horizonte, v. 10, n.1, pp. 19-28, 2005.

QUELUZ, Gilson Leandro. 0 Batismo da Máquina: Representações de Tecnologia em Alceu Amoroso Lima. Fênix (UFU. Online), v. VII, pp. 1-23, 2010.

QUELUZ, Gilson Leandro; MERKLE, Luiz Ernesto. Ciência, Tecnologia e Desenvolvimento Nacional no Pensamento de Álvaro Vieira Pinto e Alberto Guerreiro Ramos (1956-1964). In: KERBAUY, Maria Teresa Miceli; ANDRADE, Thales Haddad Novaes de; HAYASHI, Carlos Roberto Massao. (Orgs.). Ciência, Tecnologia e Sociedade no Brasil. Campinas: Alínea, 2012, v. 1, pp. 1-20.

QUELUZ, Marilda Lopes Pinheiro. A cidade reinventada nas charges de Yantok. Iluminuras (Porto Alegre), v. 15, pp. 198-211, 2014.

SANTOS, Marinês Ribeiro. Domesticidade e identidades de gênero na revista Casa \& Jardim (anos 1950 e 60). Cadernos Pagu (UNICAMP), v. 36, pp. 257-282, 2011.

SITTON, John F. Habermas and contemporary society. New York: Palgrave Mac Millan: 2003.

SUGAYAMA, Soraya. Um olhar acerca da tecnologia no teatro de rua: a tecnologia como meio de ação, mediando saberes, processos e fazeres humanos. 2012. 207 f. Dissertação (Mestrado em Tecnologia) - Programa de Pós-Graduação em Tecnologia, Universidade Tecnológica Federal do Paraná.

SUMMER, Jeniffer. Relations of Suspicion: Critical Theory and Interdisciplinary Research, History of Intellectual Culture, 2003, v.3, n. 1, pp. 1-12.

THOMASSEN, Lasse. Deconstructing Habermas. New York: Taylor \& Francis, 2008 VELASCO, Juan. Para ler a Habermas. Madrid: Alianza Editorial, 2003.

VILLAR, Maria Helena Saburido. A Fotografia estenopéica revisitada: desconstrução da homologia tradicional através das dimensões sócio-culturais da tecnologia. 2008. 249 f. Dissertação (Mestrado em Tecnologia) - Programa de Pós-Graduação em Tecnologia, Universidade Tecnológica Federal do Paraná. 
WIGGERSHAUS, Rolf. A escola de Frankfurt. DIFEL: São Paulo, 2002.

WILLIAMS, Raymond. Marxismo y literatura. Buenos Aires: Las Cuarenta, 2009.

Recebido em julho de 2014

Aprovado em fevereiro de 2015

Gilson Leandro Queluz é doutor em comunicação e semiótica pela Pontifícia Universidade Católica de São Paulo, realizou estágio pós-doutoral em política científica e tecnológica na Universidade Estadual de Campinas e professor da Universidade Tecnológica Federal do Paraná. E-mail: gqueluzlagmail.com 